\title{
10. The Doctrine of Double Effect and the Ethics of Dual Use
}

\author{
Suzanne Uniacke
}

Is the doctrine of double effect (DDE) relevant to dual-use dilemmas? Can consideration of the DDE make a significant contribution to the ethics of dual use? Several writers assume that dual-use dilemmas are instances of double effect. ${ }^{l}$ Certainly this particular connection is strongly suggested by the terms 'dual use' and 'double effect' and also by the structure of dual-use dilemmas. A dual-use dilemma is said to arise when an action or activity such as research in the life sciences or publication of that research can have both good and bad effects: alongside its intended good outcome, for example, the enhancement of knowledge or human improvement, there can also be a foreseeable bad effectfor example, assisting in the production of bioweapons. Since the doctrine, or principle of double effect as it is sometimes called, is specifically intended as a guide to decision-making in ethically difficult cases where an action or course of action with an intended good effect can also produce a foreseen bad effect, it is natural to consider whether the moral guidance that the doctrine offers in cases of double effect is also applicable to dual-use dilemmas.

In order to answer the questions posed above we need an understanding of the DDE and its intended role in practical ethics. I provide these in the next section of the chapter. According to the account of the DDE that I shall outline, dual-use dilemmas are not paradigm instances of double effect. Nonetheless, as I go on to explain, because dual-use dilemmas have significant features in common with typical instances of double effect, some important considerations that can arise in relation to the DDE and its practical application are important to providing a satisfactory account of the ethics of dual use.

\section{The doctrine of double effect}

The DDE is concerned with the application of normative moral theory to practical moral problems. It takes its rationale from the view that certain actions are morally objectionable because of the types of actions they are. Those who invoke the DDE in particularly difficult cases hold that what an actor intendsthat is, what she aims to achieve by her action - can itself be highly significant

1 See, for example, Briggle, A. 2005, 'Double effect and dual use', in C. Mitcham (ed.), Encyclopaedia of Science, Technology and Ethics. Volume 2, rev. edn, Macmillan, London, pp. 543-6. 
to the morality of what she does. This view can take absolutist and nonabsolutist forms. In its absolutist form, it holds that certain types of actions, such as intentionally killing an innocent person, are intrinsically wrong and always morally impermissible (absolutely prohibited). A non-absolutist version maintains a very strong moral constraint against certain types of actions such as those that involve the intended killing of an innocent person; on this view, such actions are always intrinsically morally objectionable even if in extreme circumstances they might be necessary in the absence of any morally acceptable alternative. $^{2}$

Not all prominent contemporary normative moral theories regard an actor's intention as directly morally significant in this way. An entirely outcomeoriented (consequentialist) theory such as utilitarianism, for instance, does not share the assumptions on which the DDE is founded and thus regards the DDE as irrelevant to the moral evaluation of actions that have both good and bad effects (including instances of dual use). Furthermore, some of those who accept or are sympathetic towards the moral assumptions behind the DDE nevertheless regard the DDE itself as problematic in some respects. There is an extensive critical philosophical literature on issues surrounding the DDE, which obviously cannot be explored here. ${ }^{3}$ Since the principal purpose of this chapter is to address the relevance of the DDE to the ethics of dual use, I shall assume as a modus operandi that there is a morally significant difference between a bad effect of an action that the actor intends and one that she foresees but does not intend and that this distinction can be directly relevant to the moral evaluation of some actions that have both good and bad effects. This assumption can be disputed but it represents a widely accepted view.

A key to understanding the nature and purpose of the DDE can be found in its origins. St Thomas Aquinas appealed to a distinction between an intended, as opposed to a foreseen, effect of an action in his explanation of why it can be permissible to kill another person in self-defence. ${ }^{4}$ Homicide in self-defence posed a problem for Aquinas because he held the more general position that it is never permissible for a private person to engage in intentional killing. Does this view imply that I cannot legitimately use lethal force on an unjust attacker if it is necessary to save my own life? In responding to this question, Aquinas claimed that the act of fending off an attacker can have two effects: a good effect (saving one's own life), which the self-defending actor intends, and also

\footnotetext{
2 This latter position is sometimes referred to as threshold deontology. See Alexander, L. and Moore, M. 2007, 'Deontological ethics', in Stanford Encyclopedia of Philosophy, Stanford University Press, Stanford, Calif., <http://plato.stanford.edu/entries/ethics-deontological/> (viewed 6 February 2012).

3 See, for example, McIntyre, A. 2009, 'Doctrine of double effect', in Stanford Encyclopedia of Philosophy, op. cit., <http://plato.stanford.edu/entries/double-effect/> (viewed 6 February 2012).

4 Aquinas, St Thomas 1966, Summa Theologiae, vol. 38, Blackfriars edn, Eyre \& Spottiswood, London, 2a, 2ae, 64, article 7 .
} 
a bad effect (the attacker's death), which the actor can foresee but need not intend. Thus, Aquinas maintained, homicide in genuine self-defence does not contravene an absolute prohibition against intended killing.

The distinction between an action's intended effects and those effects that the actor foresees but does not intend is central to what later came to be known as the doctrine of double effect. Subsequent to Aquinas's discussion of homicide in self-defence, the DDE was developed as part of natural-law reasoning about the morality of a range of actions that can have both good and bad effects, where the bad effect is something that it would be wrongful to intend. (Those who invoke the DDE in cases of double effect need not share Aquinas's view that homicide in self-defence against an unjust attacker is always unintended killing or that it must be justified as such. ${ }^{5}$ In contemporary applications of the DDE the foreseen bad effect in question is usually the death of an innocent person.) In its traditional form, the DDE is now a general principle of practical ethics that holds that in some circumstances and under specific conditions it is morally permissible to cause a foreseen bad effect of a type that is always morally wrong to intend. These conditions are

1. the act itself must be morally good or at least indifferent

2. the agent must not positively will (intend) the bad effect

3. the good effect must be produced directly by the action, not by the bad effect

4. the good effect must be sufficiently desirable to compensate for the bad effect. ${ }^{6}$

Although the DDE has its origins in Thomistic and natural-law ethics it has been taken up more widely as part of secular moral thinking by those who maintain that whether or not an actor intends to bring about a particular bad outcome, such as an innocent person's death, is itself a morally significant feature of her action that can make a difference to the morality of what she does. For instance, the DDE is frequently invoked in a number of prominent contemporary contexts, most notably in relation to the ethics of war and to issues of medical ethics. These applications include the foreseen killing of noncombatants as an incidental effect of aiming at a military target, the use of triage in hospital emergency rooms and on battlefields, some cases of risky surgery, and the administration of increased doses of pain relief that suppress respiration. ${ }^{7}$ It is perhaps worth pointing out here that within its natural-law context, the DDE was developed

\footnotetext{
5 For a critical discussion, see Uniacke, S. 1994, Permissible Killing: The Self-Defence Justification of Homicide, Cambridge University Press, Cambridge, ch. 4.

6 A fuller statement can be found in the New Catholic Encyclopedia, 1967, vol. 4, McGraw-Hill, New York, pp. 1020-2.

7 See Uniacke, S. 2007, 'The doctrine of double effect', in R. Ashcroft et al. (eds), Principles of Heath Care Ethics, 2nd edn, Wiley \& Sons, Chichester, UK.
} 
and is characterised as a guide to decision-making in morally difficult cases where an action will have both good and bad effects; however, many recent secular philosophical discussions seem to assume that the DDE's plausibility depends on its ability to give a definitive answer about morally permissible action in every conceivable problem to which it might be applied.

As noted earlier, the DDE derives from the view that irrespective of their overall effects on the world, some actions are morally objectionable as the types of actions they are - for instance, as instances of intentional killing. There are obvious practical difficulties for this view, especially (but not exclusively) in circumstances of emergency where the alternative actions available to an agent are severely restricted. Consider the following example. My car's brakes fail on a hill and I need to swerve to the left in order to avoid oncoming traffic and also some children who are on a pedestrian crossing in front of me. If I swerve to the left I will hit and could seriously injure or kill a pedestrian who has just stepped out from the curb. Is it permissible to swerve the car in these circumstances? (Since I will hit oncoming traffic and the children if I do not swerve, if it is not permissible to swerve, will I act impermissibly whatever I do?) In this particular example the DDE says it is permissible to swerve. My swerving the car is not in itself a morally impermissible type of act. (The morality of swerving a car depends on the circumstances and on why I swerve.) If I swerve the car to the left in these particular circumstances, this would have two distinguishable, independent effects: an intended good effect (avoiding oncoming traffic and the children) and also a foreseen bad effect (hitting a pedestrian) that is strictly incidental to what I intend to do in swerving the car.

According to the DDE, a foreseen effect is strictly incidental to the actor's intention if it is not part of what the actor aims to achieve either as an end or as a means of achieving an end in the circumstances. ${ }^{8}$ If at the time of swerving the car I were to ask myself whether my intention would be fulfilled if, against expectation, I happen not to hit or kill the pedestrian, I can honestly answer yes. The presence and position of the pedestrian and any harm he might suffer are irrelevant both to my swerving to the left in order to avoid oncoming traffic and the children and also to how I achieve that aim in the circumstances. (It would be misleading not to point out here that there are vexed philosophical issues about intention and its moral significance in relation to the DDE. ${ }^{9}$ To address those deeper issues would take us too far into a discussion of the DDE itself. Suffice to say that despite these critical issues there are cases of double

8 Incidental effects of an action are not necessarily bad or unwelcome. Consider, for example, taking on hard manual labour solely in order to earn money and becoming physically very fit as a result.

9 See, for example, Kamm, F. M. 2000, 'The doctrine of triple effect and why a rational agent need not intend the means to his end', Proceedings of the Aristotelian Society, Supplementary Volume, vol. 74, no. 1, pp. 21-39; McIntyre, A. 2001, 'Doing away with double effect', Ethics, vol. 111, no. 2, pp. 219-55; and McIntyre, 2009, op. cit. 
effect, including the example just described, where a foreseen bad effect of an action is clearly incidental to what the actor aims to achieve in acting as she does.) While the actor's intention is central to the guidance offered by the DDE it is not the sole consideration. For an act of double effect to be permissible the intended good effect must also be sufficiently morally weighty in comparison with the foreseen bad effect to warrant causing the bad effect. The DDE's fourth condition requires a judgment of proportionality. This particular condition could permit my swerving the car in order to avoid hitting a greater number of innocent people in the circumstances described above, but it would not permit, for example, my swerving a car in the direction of a pedestrian in order to avoid hitting a dog or damaging property.

An obvious question is why we should bother with a distinction between intention and foresight in circumstances such as these. Why not simply consider something like the DDE's fourth condition and compare the probable outcomes of the available alternatives (for example, to swerve or not to swerve) and say that someone who is faced with making such a decision should act so as to save as many innocent people as possible? Those who think that the DDE is morally significant in such cases would reply that if we simply appeal to a principle that tells us to save as many innocent people as possible and do not also invoke a distinction between an effect that an actor intends as opposed to an effect that she (merely) foresees, we commit ourselves to killing some innocent people as a means of saving others, and this is morally unacceptable. It is one thing that I put the life of a pedestrian in grave danger in swerving the car in order to avoid hitting a greater number of people; it would be another thing to cause the death of innocent person as a means of preventing harm to a greater number by, for example, using an innocent person as a human shield.

A related point is that according to the DDE, actions of double effect that meet its four conditions are morally permissible. (They are not necessarily the right thing to do all things considered or what the actor is morally required to do.) If under the fourth condition the foreseen bad effect is disproportionate in relation to the intended good effect then the action under consideration is held to be impermissible. The fourth condition does not represent an all-thingsconsidered judgment based on the action's predicted or actual overall outcome. This point of clarification is important in the context of a discussion of the application of the DDE to the ethics of dual use because dual-use dilemmas are often explicitly discussed solely in cost/benefit terms, as being entirely a matter of whether the overall likely benefits of an activity's good use can be 'traded off' against and would outweigh the risks of its malevolent or negligent use. As with actions of double effect, however, the basic question posed by a 'dual-use 
dilemma' is, I take it, whether it would be morally permissible to engage in the activity in question given the risks of its misuse, and not whether it would be morally right or morally obligatory to do so.

\section{Double effect and dual use}

It is easy to see why one might regard dual-use dilemmas as instances of double effect. A dual-use dilemma arises when an action or activity has both an intended good use and a possible malicious or negligent use. Structurally this looks very much like a case of double effect; however, dual-use dilemmas are also dissimilar to paradigm instances of double effect in a number of respects. For instance, in the above example my decision whether to swerve the car is a forced choice in circumstances in which I have little time for deliberation and extremely limited options. This is the situation in many instances of double effect whereas dualuse dilemmas are usually not like this. But we can set this particular dissimilarity aside; although the DDE is often applied to situations of forced choice where the actor has little time for reflection or practical manoeuvre, this is not necessary to double effect, and very familiar applications of the DDE in medical contexts and in war do not display these features.

Other dissimilarities between double effect and dual use are, however, more significant. In typical instances of double effect the actor foresees the bad effect as morally certain or highly probable; the bad effect is usually also an unavoidable and a direct effect of the action that produces the good effect. (This is true of my swerving the car in the above example, for instance.) These particular features have implications for what is required under the DDE's four conditions, fuller statements of which say that in coming to a judgment under condition (4) a foreseen bad effect that is morally certain to occur should weigh more heavily (ceteris paribus) than one that is merely probable; they also specify that if the actor could obtain the intended good effect without also producing the foreseen bad effect he should do so. (A reasonable interpretation of this latter directive will inevitably involve considerations of comparative cost and risk, but it clearly implies that, for example, if I swerve the car I must try to warn the pedestrian of the danger by, say, tooting the car's horn.) By contrast, an actor facing a dual-use dilemma who foresees a bad use as a possibility is often unable to ascertain the probability of its occurring; this is partly because the bad use, if it occurs, is indirect and dependent upon the further agency of another person.

The resolution of dual-use dilemmas must obviously address the extent to which an actor can reasonably foresee the harmful use of something that she intends for a good purpose. Such judgments are notoriously difficult, particularly 
because they involve the actions of others, and this epistemological difficulty is prominent in the literature on the ethics of dual use in relation to the socalled precautionary principle. ${ }^{10}$ What is less often highlighted is that dual-use dilemmas also involve the complex question of the moral significance of another person's further agency in relation both to the degree to which I ought to take this into account in deciding what it is permissible for me to do and to the degree to which by acting in a certain way I am morally obliged to try to prevent the further agency of another person or its bad effects. Above I have brought out this moral complexity by identifying a number of dissimilarities between dual-use dilemmas and typical cases of double effect. Might considerations that inform the DDE and the debate surrounding its application nonetheless assist us in reasoning about this moral issue in relation to dual use? I will suggest in the next section that they can.

Prior to that discussion, as a crucial first step, we must ask whether the DDE is applicable to cases in which the foreseen bad effect is due to the agency of another person. (If it is not then dual-use dilemmas are not instances of double effect.) I see no reason in principle why it cannot be. Consider a modified version of the earlier example in which my car's brakes fail, but where I will hit the pedestrian only because when I swerve to the left he will be jostled into the path of my car by someone else. We can also think about the DDE in relation to a case of duress. Say the Gestapo threatens to torture or kill an innocent hostage unless I tell them the whereabouts of a Jewish family in hiding. In resisting this threat I foresee but I do not intend the injury that the Gestapo will inflict on an innocent hostage, even if I could prevent it by giving in to the threat. In a third type of case, we might apply the DDE to my decision to work as a bartender, where in taking up such a position I foresee that despite taking due care, at some future point I will almost certainly serve alcohol to someone who will then drive while intoxicated and possibly injure or kill someone.

If the DDE is indeed applicable to examples such as the three just described, in which a foreseen bad effect is due to the agency of another person, we cannot conclude simply on this basis that the DDE is therefore applicable to dual-use dilemmas. This is because there are also various respects in which each of these three examples differs structurally from a dual-use dilemma. For instance, in the first, modified car-swerving example, although the bad effect is contingent upon the intervening agency of another person (who jostles the pedestrian into the path of my car), nonetheless I will directly hit the pedestrian by swerving

10 This is a general principle that states that if an action or activity has a suspected risk of causing serious harm to the public or to the environment, if experts disagree about whether the action or activity will or is likely to cause this harm, it is up to those proposing to undertake the action or activity to prove that it will not cause this harm. The implication of the principle is that without such proof they should not proceed. 
my car. ${ }^{11}$ In the second, duress example, the act in question (my refusal to reveal the family's whereabouts to the Gestapo) is a negative action, as opposed to something that I do; furthermore, even if I could protect the innocent hostage by telling the Gestapo what they want to know, the injury inflicted on the hostage will be wholly due to the actions of another agent (the Gestapo). In the third, bartender example, the action in question is my assumption of a longerterm activity, as opposed to an individual action of double effect. Nonetheless, the third example is probably structurally the closest to an instance of dual use of the three examples, in that it involves positive action on my part with a foreseen bad effect that is both indirect and due to the agency of another person. More importantly, the third example also shares a crucial feature with dual-use dilemmas that is missing in the second, duress example, but is present in the first, modified car-swerving example. And this is that in the circumstances as they actually occur, my positive action plays a specific causal role in bringing about the bad effect - namely, it enables or aids another person to do something wrongful (to jostle the pedestrian into the path of my car/to drive while intoxicated/to create a bioweapon). (In the second example, on the other hand, my refusal to give in to the Gestapo's threat does not enable them to torture or kill the innocent hostage: it does not provide them with the means.) For this reason, in the first and the third examples the description of the foreseen bad effect of my positive action includes enabling or aiding the wrongful action of a third party, and this is also true of dual-use dilemmas where what I do (for example, publish research) enables or aids its malicious or negligent use.

The fact that in each of these cases the further actions of another agent are properly regarded as a foreseen bad effect of my action presses the following question: under what conditions am I responsible for the actions of another person in the sense that I must regard what he or she does as an effect of what I do for which I can be accountable? This is a broad and complex question that clearly cannot be addressed in detail in this chapter. Nevertheless, in the next section I shall identify considerations relevant to the DDE that can also shed important light on how we should answer this question in the case of dual-use dilemmas.

\section{Responsibility for a foreseen bad effect}

The DDE does not say that a person is not responsible for the foreseen bad effect of his action provided this effect is unintended and proportionate to an intended

11 Whether we would regard the jostling as (merely) part of circumstances in which I swerve the car, as opposed to a primary cause of the pedestrian's being hit, could depend on whether it was accidental or inadvertent (simply a result of a crowded footpath, for instance), as opposed to an intended, negligent or malicious action. 
good effect. On the contrary, according to the DDE the actor is responsible for the bad effect in an important sense-namely, that she must take it very seriously into account in deciding how to act and she must morally account for having brought it about or not prevented it when she might have done otherwise. ${ }^{12}$ As an upshot of this responsibility for the bad effect, the actor must try to achieve the good effect without the bad if she can possibly do so. It might uncritically be assumed that this type and degree of responsibility for the bad effect are due to the fact that in typical cases of double effect although the bad effect is unintended it is both a foreseen and a direct effect of what the actor chooses to do. Certainly these features strengthen the case for attribution of responsibility for the bad effect. But they are not necessary to such attribution. In the first (modified car-swerving) and the third (bartender) examples discussed earlier, the foreseen bad effect of my action incorporates the agency of another person, and this is something that I must take into account in deciding how to act and for which I can be called to account. To be sure, in the first example, the bad effect is directly and strongly connected to my swerving the car, but the connection is less direct in the third example in which my serving someone alcohol might be a sufficient but not a necessary condition of his being intoxicated and also an indirect cause of his driving in this condition. In both these examples, attribution of responsibility for the bad effect to my own agency is due in large part to the enabling role that my positive action plays in the further agency of another person. And this will also be true of cases of dual use.

At this point I would like to suggest that I am responsible for the bad effect of another person's further agency, in the sense that I must take it into account in deciding how to act and I can be accountable for it (and will bear a degree of culpability for it in the absence of justification or excuse) if at the time of my own prior action: 1) I can reasonably foresee that another agent will bring about this effect; and 2) in acting as I do I provide someone else with the means or the opportunity to bring about this effect. ${ }^{13}$ Discussions of dual-use dilemmas tend to focus on the first of these two conditions - that is, on the extent to which another person's further agency is reasonably foreseeable and on the probability of the suspected bad effect actually occurring. In drawing attention to the significance of the second condition, I hope to emphasise that where these two conditions are met, although the bad effect is indirect and due to the agency of

\footnotetext{
12 Adherents to the DDE regard our obligation to prevent harm as generally less stringent than our obligation not to do harm. Nonetheless, they also hold that it can be wrong not to prevent harm to an innocent person, particularly where this is an intended effect of one's inaction. It can be important to the permissibility of some instances of non-prevention of harm (for example, some decisions not to rescue) that the harm although foreseen is not intended.

13 Note these two conditions say 'if' and not 'only if'. Some people would also regard me as responsible in this sense for what the Gestapo does to the innocent hostage in the second example. But a person's responsibility for a foreseen outcome of her negative action is a much more contentious issue, especially where it also involves the further agency of someone else, and needn't be taken up here.
} 
another person, my contribution to bringing about the bad effect is strong in virtue of the fact that I both foresee and enable it. Under these two conditions, I am responsible for the bad effect in the robust sense outlined above. Moreover, responsibility in this sense also generates an agent-related obligation on my part to try to prevent the bad effect if possible. Although the bad effect, if it occurs, will be an indirect effect of my action that is due to the further agency of someone else, because it is nonetheless something that I have enabled or aided, my obligations in this regard are stronger than any general obligations one might have to prevent harm or wrongdoing by others.

\section{Concluding remarks}

I have maintained in this chapter that dual-use dilemmas are not paradigm instances of double effect and I have identified significant similarities and dissimilarities between the two. All the same, our critical thinking about whether the DDE and its conditions are indeed relevant to dual-use dilemmas has served to highlight some morally important aspects of the ethics of dual use that might otherwise not receive sufficient critical attention. These include the relevance of a distinction between foresight and intention to the moral permissibility of an action with both good and bad effects; the conditions under which we are accountable for the further agency of other people who bring about a bad effect; and the relatively stringent agent-related obligation to prevent harm or wrongdoing by others where one's action would provide them with the means or the opportunity. A suitably morally complex ethical evaluation of dual use needs to address these various issues. But in a more sceptical vein we can ask whether we need to refer to the DDE in order to do this.

The DDE is centrally concerned with the moral relevance of a distinction between intention and foresight, since this distinction is held to be crucial to permissible action in cases of double effect. It is clear in the case of a dual-use dilemma that the foreseen bad use is not intended by the agent who faces the dilemma (although it may well be intended by the further agent who engages in the bad use). According to the DDE, the fact that an actor does not intend a foreseen bad effect of her action can be highly significant to the moral permissibility of what she does. This then will also be a consideration in deliberation about the permissibility of activities that are potentially dual use. The DDE also emphasises that in cases of double effect the fact that the bad effect is foreseen is itself morally significant to the permissibility of the action. The actor must take the bad effect seriously into account in her deliberations and her action must be justified in terms of a good effect that is sufficiently morally important to warrant causing the bad effect. And as I have argued above, this can be so in cases of double effect where the bad effect will be indirect and due to the further 
agency of another person. Furthermore, we can be responsible in the sense of being accountable for the harmful or wrongful actions of other people if by our own actions we have enabled or aided them. This means that our obligation as agents not to do harm extends to the obligation not to provide others with the means of doing harm; while not an absolute obligation, it is nonetheless a strong one. It also means that our obligation to prevent harm being done by others becomes a more stringent, agent-related obligation when the harm in question is something that we ourselves have provided others with the means of doing. These obligations are particularly salient to the ethics of dual use. 